\title{
A MULTILINEAR RELLICH INEQUALITY
}

\section{DAVid E. EDMunds And ALEXANDER MESKHI*}

Abstract. We prove a multilinear variant of the Rellich inequality on the real line. In particular, we establish the weighted inequality

$$
\left(\int_{a}^{b} w(\delta(x))\left|\prod_{k=1}^{m} u_{k}(x)\right|^{p} d x\right)^{1 / p} \leqslant C \prod_{k=1}^{m}\left\|u_{k}^{\prime \prime}\right\|_{L^{p_{k}(a, b)}}, u_{k} \in C_{0}^{2}(a, b), \quad k=1, \ldots, m,
$$

with a positive function $w$ on $(0, b-a))$, where $-\infty \leqslant a<b \leqslant+\infty, m$ is a positive integer, $\delta(x)=\min \{x-a, b-x\}$ is the distance function on $(a, b)$, and $1 / p=\sum_{j=1}^{m} 1 / p_{j}, p_{j}>1$, $j=1, \ldots, m$. As a corollary we derive the following estimate

$$
\left(\int_{a}^{b}\left|\prod_{j=1}^{m} u_{j}(x)\right|^{p} \delta(x)^{-2 m p} d x\right)^{1 / p} \leqslant C \prod_{j=1}^{m}\left\|u_{j}^{\prime \prime}\right\|_{L^{p_{j}}(a, b)} .
$$

Mathematics subject classification (2010): 26A42, 35A22, 35A23.

Keywords and phrases: Weighted Rellich inequality, multilinear Hardy inequality, two-weight inequality.

\section{REFERENCES}

[1] M. I. Aguilar Canstro, P. Ortega Salvador and C. Ramires Torreblan, Improved Rellich inequalities for the polyharmonic operator, Indiana Univ. Math. J., 387 (2012) 320-334.

[2] A. BALINSKY, W. D. EvANS AND R. T. LEWIS, The analysis and geometry of Hardy's inequality, Springer, New York, 2015.

[3] E. B. Davies AND A. M. HinZ, Explicit constants for Rellich inequalities in $L_{p}(\Omega)$, Math. Z., 227 (1998), 511-523.

[4] D. E. Edmunds And W. D. Evans, The Rellich inequality, Rev. Math. Complut., 29, 3 (2016), $511-530$

[5] D. E. Edmunds And A. MeSKHI, Two-weighted Hardy operator in $L^{p(x)}$ spaces and applications, Studia Math. 249 (2019), 143-162.

[6] W. D. Evans AND R. T. LewIS, Hardy and Rellich inequalities with remainders, J. Math. Inequal. 1, 4 (2007), 473-490.

[7] L. Grafakos, Classical Fourier analysis, Springer, Third Edition, New York, GTM 249, 2014.

[8] A. KufNer AND L.-E. Persson, Weighted inequalities of Hardy type, World Scientific, Singapore, 2003.

[9] F. Rellich, Halbbeschränkte Differentialoperatoren höherer Ordnung, In: Gerretsen, J.C.H., de Groot, J. (eds.) Proc. Int. Nat. Congress of Mathematicians 1954, vol. III, pp. 243-250. Noordhoff, Groningen, 1956. 